\title{
Amyloid goitre
}

\author{
P. D. JAMES ${ }^{1}$
}

From the Department of Pathology, Makerere University Medical School, Kampala, Uganda

SYNOPSIS Amyloid goitre is a rare manifestation of amyloidosis; about 50 cases have been recorded and this paper adds a further six cases, the first to be described from Uganda. The condition has to be distinguished from the more common types of goitre, and histological differentiation from medullary carcinoma may be difficult with small biopsies.

Irrespective of an underlying cause, the distribution of amyloidosis in Uganda resembles the classical secondary type, and the findings in 81 cases confirm this. The age of onset of the primary type is earlier than seen elsewhere and it is possible that these variations result from immune depression following malnutrition or endemic infectious diseases.

Amyloid goitre, an enlargement of the thyroid due to widespread amyloid infiltration, is a rare phenomenon. Shapiro, Kohut, and Potter (1971) recorded 47 cases from the world literature. In Uganda, six cases of amyloid goitre have been seen since 1960 and represent a relatively high incidence of this unusual manifestation of systemic amyloidosis.

The distribution of amyloid material in Ugandans suffering from systemic amyloidosis differs from that seen elsewhere (Wright, 1961). A further survey of systemic amyloidosis in Uganda has been carried out to investigate this finding.

\section{Materials and Methods}

Five cases of amyloid goitre were seen at necropsy in Mulago Hospital, Kampala, between January 1961 and April 1971; these were discovered only at necropsy and in each case the gland weight exceeded $40 \mathrm{~g}$. During this period 9274 necropsies were performed. Material from a sixth case was submitted

${ }^{1}$ Address for reprints: The Bland Sutton Institute of Pathology, The Middlesex Hospital Medical School, London W1.

Received for publication 23 February 1972. for histological examination following subtotal thyroidectomy.

Sections were cut from the original paraffin blocks, where available, stained with haematoxylin and eosin, Congo red and thioflavine $T$, and studied to assess the distribution of amyloid. The presence of amyloid was confirmed in all cases by its avidity for Congo red stains, the green-yellow birefringence with Congo red stains viewed by polarized light, and the ultraviolet fluorescence with thioflavine $T$.

\section{Clinical Summaries}

Three patients were male and three female. The ages at diagnosis ranged from 24 to 70 with a mean of 40. Table I summarizes the relevant findings. In three cases no underlying cause for amyloidosis was found; pulmonary tuberculosis was found in two cases and one patient had a chronic leg ulcer. Three patients presented in congestive cardiac failure, one being secondary to renal hypertension; another presented with the nephrotic syndrome. Pressure symptoms had not been noted in any of the cases where amyloid goitre was discovered at necropsy

\begin{tabular}{lllrlll}
\hline Case & Age & Sex & Thyroid Weight $(g)$ & Presentation & Underlying Disease \\
\hline 1 & 45 & F & 70 & Congestive cardiac failure & None \\
2 & 49 & M & 140 & Chronic leg ulcer & Chronic leg ulcer & Severe anaemia \\
3 & 24 & M & 90 & Nephrotic syndrome & Pulmonary tuberculosis & None \\
4 & 70 & M & 360 & Congestive cardiac failure & None & Chronic glomerulonephritis \\
5 & 30 & F & 50 & Congestive cardiac failure, & None & Acute pancreatitis \\
6 & 25 & F & 145 & Dysphagia & Pulmonary tuberculosis & None \\
\hline
\end{tabular}

Table I Summary of case findings in six patients with amyloid goitre 


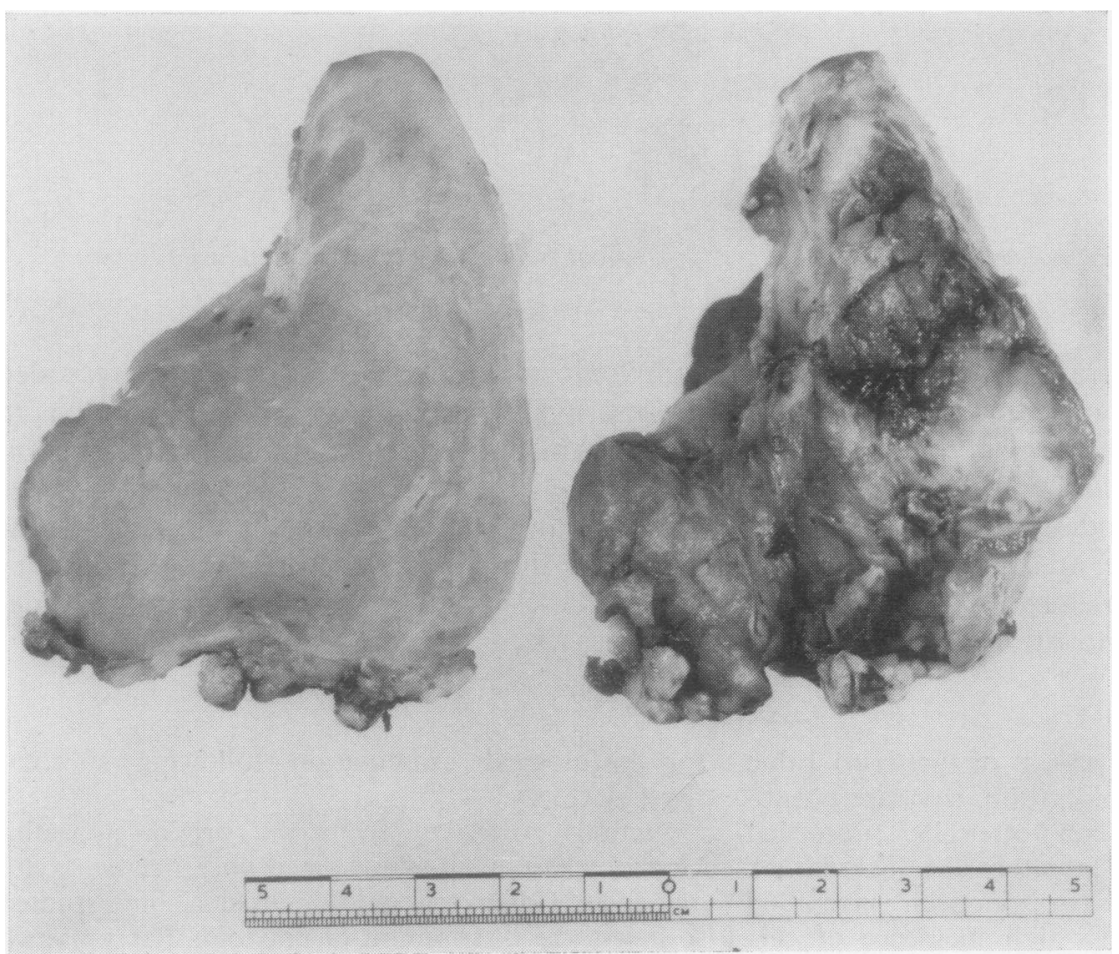

Fig. 1 Partial

thyroidectomy specimen showing cut surface and $\vec{\circ}$ medial surfaces with tracheal indentation in case 6 (scale in $\mathrm{cm})$.

but sudden enlargement of the gland may have contributed to death in case 2. Case 6 was a 25-yearold female who complained of dysphagia. On examination she was noted to have a smooth, symmetrical goitre without retrosternal extension; partial thyroidectomy was performed. The specimen received in the laboratory weighed $145 \mathrm{~g}$ and on cross section was a yellow-white colour with a glassy appearance (Fig. 1).

\begin{tabular}{llllllll}
\hline Case $^{2}$ & Liver & Kidney & Spleen & Adrenals & Tongue & $\begin{array}{l}\text { Alimen- } \\
\text { tary } \\
\text { Tract }\end{array}$ & Heart \\
\hline $\mathbf{1}$ & $\mathbf{V}$ & $\mathbf{V}$ & +++ & $\mathbf{V}$ & + & $\mathrm{V}$ & + \\
$\mathbf{2}$ & $\mathbf{V}$ & + & $\mathbf{V}$ & + & + & - & + \\
$\mathbf{3}$ & $\mathbf{V}$ & ++ & + & - & - & - & - \\
$\mathbf{4}$ & $\mathbf{V}$ & + & $\mathbf{V}$ & - & - & - & + \\
$\mathbf{5}$ & $\mathbf{V}$ & + & $\mathbf{V}$ & $\mathrm{V}$ & - & - & + \\
\hline
\end{tabular}

Table II Distribution of amyloid material in five necropsied cases of amyloid goitre

\footnotetext{
${ }^{1}$ Case numbers are the same as for Table 1

$\mathrm{V}=$ infiltrate predominantly perivascular

$+=$ perivascular and parenchymatous infiltrate

$++=$ perivascular and marked parenchymatous infiltrate

- = no material available for examination.
}

There was no significant tribal distribution.

The distribution of the amyloid in the five necropsied cases is summarized in Table II.

\section{Microscopic Findings}

Microscopic examination of the thyroid shows. complete or near complete replacement of the thyroid parenchyma by amyloid in all cases. The infiltrate originates between the acini which ares stretched, attenuated, and the lining epithelium flattened. Occasional islands of more normal thyroios. tissue are seen (Fig. 2). A patchy, chronic inflam matory infiltrate of plasma cells and lymphocytes is often present but is seldom prominent. Occasionat foci of foreign body giant cells and epithelioid cellsu

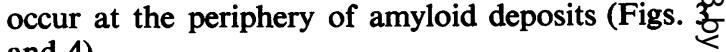
and 4).

Amyloid was present in all organs studied micro scopically. Infiltration of the liver was minimal in ale five cases and extensive infiltration of the spleen was found only in two cases. By contrast, the kidne $\bar{b}$ showed extensive perivascular, glomerular an $\Phi$ interstitial infiltration in four cases. The heard showed perivascular and some interstitial infiltration
in all four cases examined. 


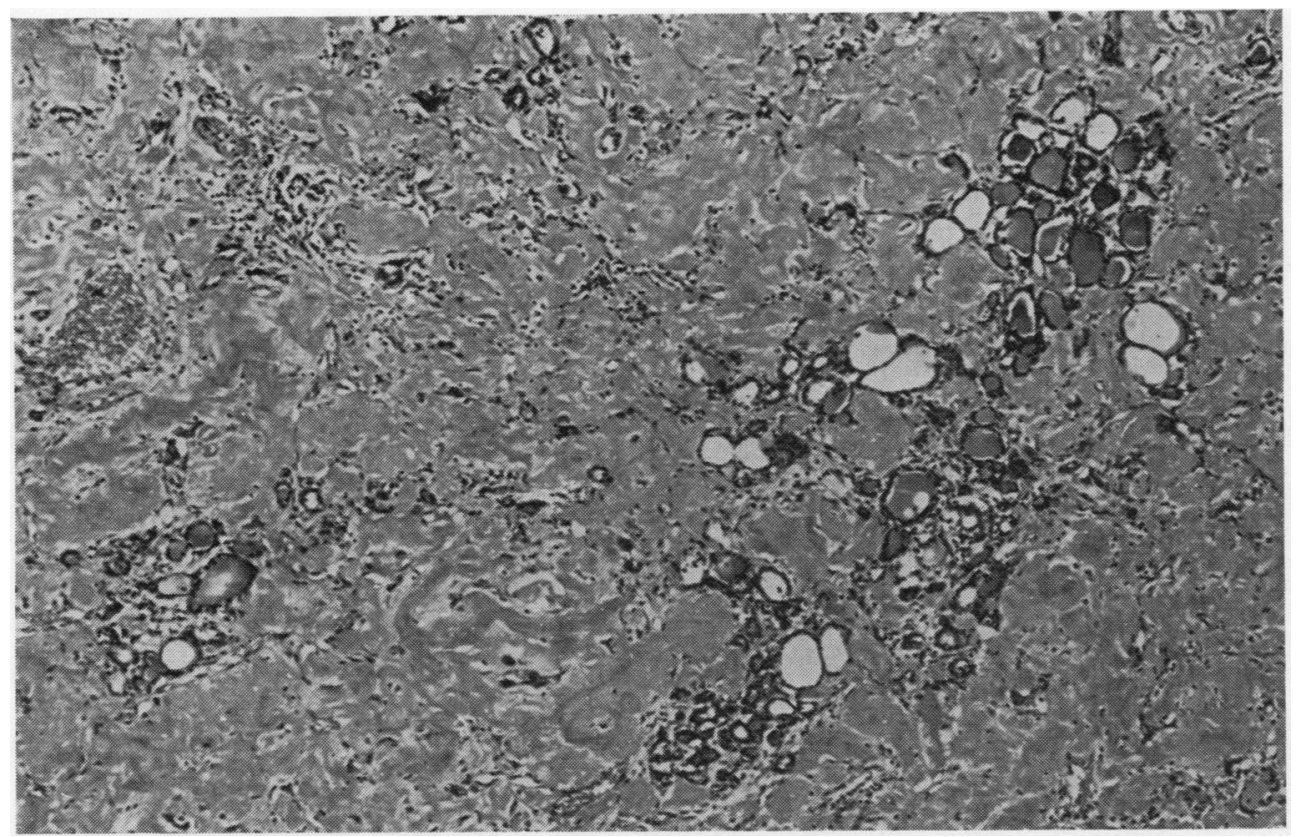

Fig. 2.

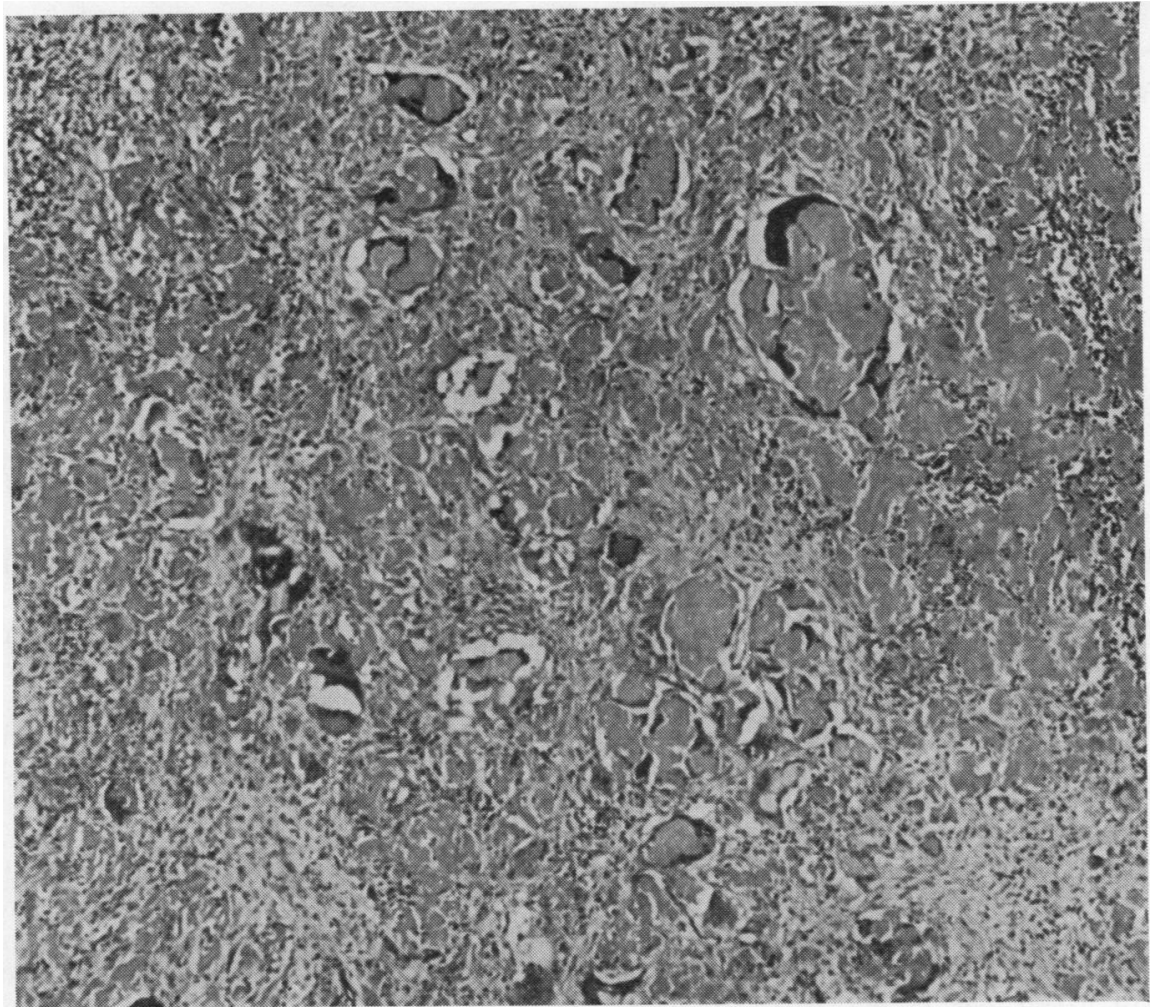

Fig. 2 The normal thyroid architecture is almost completely replaced by amyloid except for a few surviving acini in case 6 (haematoxylin and eosin $\times 50$ ).

Fig. 3 Another area with a marked giant cell reaction around the deposits of amyloid (haematoxylin and eosin $\times 50$ ).

Fig. 3. 


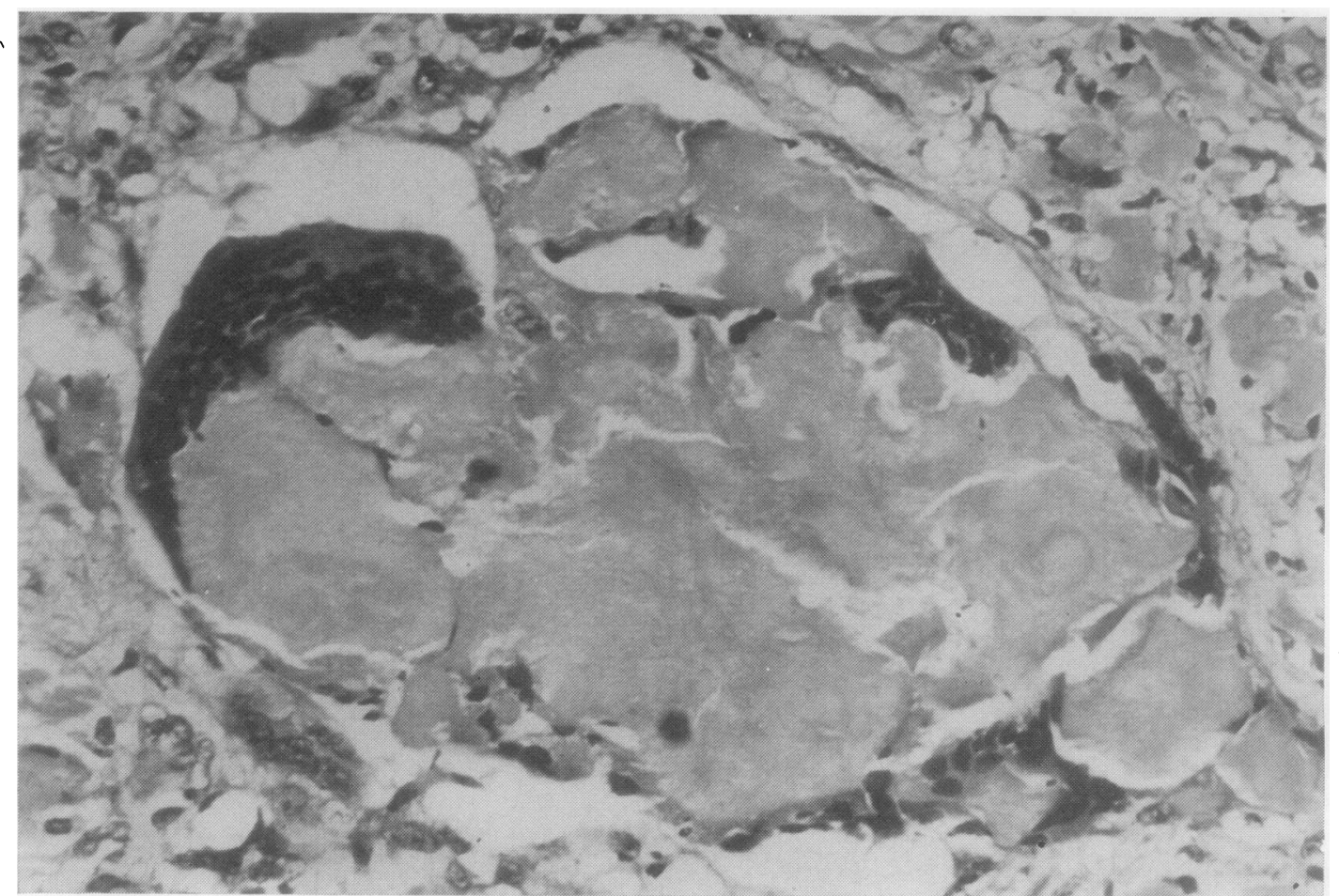

Fig. 4 A foreign body giant cell associated with deposits of amyloid in case 6 (haematoxylin and eosin $\times 300$ ).

In addition, the kidneys in cases 4 and 5 showed the changes of chronic glomerulonephritis.

\section{Discussion}

Some degree of microscopic infiltration of the thyroid is found in most cases of systemic amyloidosis, the distribution usually being strictly perivascular (minor involvement). Enlargement due to widespread infiltration (major involvement or amyloid goitre) is rare.

Amyloid infiltration of the thyroid was first described in 1855 (von Rokitansky), and the first recorded example of amyloid goitre in 1858 (Beckmann). Walker (1942) reports two cases of amyloid goitre with a review of 56 cases from the literature. Arean and Klein (1961) point out that some earlier cases included as amyloid goitre were merely examples of amyloid infiltration of the thyroid found incidentally at necropsy, and, with their stricter criteria, accept only 29 . Recently Shapiro, Koluit, and Potter (1971) recorded 47 cases from world literature, to which may be added the cases recorded by Hunter, McDougall, and Winston
Evans (1968) and by Abraham, Damodaran, ande Sharma (1967).

In Caucasian subjects microscopic involvement of the thyroid gland by amyloid can be found in $50 \%$ of primary systemic amyloidosis and $80 \%$ of the secondary type (Arean and Klein, 1961); such. infiltration is usually confined to the walls of bloof vessels and is clinically unsuspected.

Amyloid infiltration of the thyroid sufficient toㅇ produce a clinically detectable goitre is rare but when it occurs the enlargement of the gland is rapid‥ In recorded series the history ranges from fouf months to three years with an average of about one्र year. The gland is firm to hard in consistency although a few are soft; the cut surface varies inw colour from white, grey to yellow, with occasiona $\bar{P}$ areas of haemorrhage.

Clinical evidence of myxoedema is uncommon despite the widespread infiltration of the gland. $I^{+}$ occurred in none of the 29 cases reviewed by Arean? and Klein (1961) but it did, after thyroidectomy, in their own case. In the present series, none of the necropsy cases or the case diagnosed clinically ha\& any evidence of thyroid hypofunction. 
The histological diagnosis of amyloid goitre is straightforward if adequate material is available. However, amyloid goitre may show small groups of distorted cells separated by an amyloid stroma that could lead in a needle biopsy to a mistaken diagnosis of medullary carcinoma. Two cases of medullary carcinoma were found in the 80 Ugandan cases of thyroid carcinoma recorded in the Kampala Cancer Registry (Templeton, 1970).

The distribution of the amyloid deposits in the other organs of the five necropsied patients is shown in Table II. All five cases showed only perivascular involvement of the liver and only two had extensive splenic involvement. However, widespread perivascular, glomerular, and interstitial involvement was noted in the kidneys of four of the five cases. The relatively severe involvement of the kidney compared with the predominantly perivascular infiltration in other organs has already been noted in Uganda (Wright, 1961). The same author recorded 40 cases of amyloidosis from the Mulago Hospital necropsy records over a 10-year period up to 1960 ; in 26 cases no associated chronic disease was found. The thyroid had been examined histologically in seven cases of primary amyloidosis and one case of the secondary type and only two cases in the former group showed involvement; this was reported as being insignificant in both cases.

In this subsequent 10-year study on consecutive material up to the end of 1970,41 cases of amyloidosis were recorded from 9038 necropsies; this represents an incidence of $0.45 \%$. Table III shows the distribution of amyloid in these cases. There was a greater incidence of tongue, heart, and thyroid infiltration than previously reported (Wright, 1961) but otherwise the findings are similar. The kidney is involved in most cases and is usually the most severely affected organ, amyloid being found in the glomeruli, arteries, and to a lesser extent around the tubules. Minor involvement of the thyroid is present in most cases. Three cases of amyloid goitre were found in this 10-year period (the two additional cases reported came to necropsy in 1971), which is a higher relative incidence of this form of the disease than in other parts of the world. In Caucasians the distribution of amyloid in primary and secondary amyloidosis is regarded by some as very different whereas in Uganda both resemble the classical secondary type. Table IV shows the distribution of amyloid in 81 cases from Uganda (the figures are compounded from the present series and a previous study (Wright, 1961)) and compares it with primary

\begin{tabular}{|c|c|c|c|c|}
\hline & \multicolumn{2}{|c|}{13 Cases of Primary Amyloidosis } & \multicolumn{2}{|c|}{28 Cases of Secondary Amyloidosis } \\
\hline & No. Examined & No. Positive & No. Examined & No. Positive \\
\hline $\begin{array}{l}\text { Tongue } \\
\text { Heart } \\
\text { Liver } \\
\text { Pancreas } \\
\text { Spleen } \\
\text { Kidney } \\
\text { Adrenal } \\
\text { Thyroid }\end{array}$ & $\begin{array}{r}6 \\
12 \\
13 \\
11 \\
13 \\
11 \\
9 \\
5\end{array}$ & $\begin{array}{r}5(83 \%) \\
7(58 \%) \\
10(77 \%) \\
7(64 \%) \\
11(85 \%) \\
10(91 \%) \\
7(77 \%) \\
4(80 \%)\end{array}$ & $\begin{array}{r}8 \\
16 \\
25 \\
13 \\
24 \\
27 \\
13 \\
10\end{array}$ & $\begin{array}{r}6(75 \%) \\
6(37 \%) \\
18(72 \%) \\
6(46 \%) \\
22(92 \%) \\
26(96 \%) \\
9(70 \%) \\
7(70 \%)\end{array}$ \\
\hline
\end{tabular}

Table III Distribution of amyloid in 41 cases of systemic amyloidosis seen from 1961 to 1970

\begin{tabular}{|c|c|c|c|c|c|c|c|c|}
\hline & \multicolumn{3}{|c|}{$\begin{array}{l}39 \text { Cases of Primary Amyloidosis from } \\
\text { Uganda }\end{array}$} & \multirow{2}{*}{$\begin{array}{l}\text { Minimal } \\
\text { Percentage } \\
\text { Involvement } \\
\text { in Primary } \\
\text { Amyloidosis }\end{array}$} & \multicolumn{3}{|c|}{$\begin{array}{l}42 \text { Cases of Secondary Amyloidosis from } \\
\text { Uganda }\end{array}$} & \multirow{2}{*}{$\begin{array}{l}\text { Percentage } \\
\text { Involvement } \\
\text { in Secondary } \\
\text { Amyloidosis }\end{array}$} \\
\hline & No. Examined & No. Positive & $\begin{array}{l}\text { Percentage } \\
\text { Involvement }\end{array}$ & & No. Examined & No. Positive & $\begin{array}{l}\text { Percentage } \\
\text { Involvement }\end{array}$ & \\
\hline $\begin{array}{l}\text { Tongue } \\
\text { Heart } \\
\text { Liver } \\
\text { Pancreas } \\
\text { Spleen } \\
\text { Kidney } \\
\text { Adrenal } \\
\text { Thyroid }\end{array}$ & $\begin{array}{r}8 \\
24 \\
31 \\
20 \\
28 \\
37 \\
26 \\
12\end{array}$ & $\begin{array}{r}5 \\
9 \\
21 \\
10 \\
23 \\
35 \\
19 \\
6\end{array}$ & $\begin{array}{l}62 \\
38 \\
68 \\
50 \\
82 \\
95 \\
73 \\
50\end{array}$ & $\begin{array}{l}40 \\
90 \\
35 \\
40 \\
35 \\
25 \\
-\end{array}$ & $\begin{array}{l}10 \\
24 \\
35 \\
18 \\
30 \\
40 \\
22 \\
11\end{array}$ & $\begin{array}{r}7 \\
8 \\
24 \\
9 \\
28 \\
37 \\
14 \\
7\end{array}$ & $\begin{array}{l}70 \\
33 \\
69 \\
50 \\
93 \\
92 \\
64 \\
64\end{array}$ & $\begin{array}{r}-43 \\
87 \\
63 \\
100 \\
93 \\
93 \\
59\end{array}$ \\
\hline
\end{tabular}

Table IV Distribution of amyloid in 81 cases $^{1}$ of systemic amyloidosis from Uganda compared with those in primary and secondary amyloidosis from outside Africa

${ }^{1}$ These figures are a combination of a previous 10-year study (Wright, 1961) and the present series.

Minimal percentage involvement in 145 cases of primary amyloidosis (Symmers, 1956).

'Percentage involvement in secondary amyloidosis (Dahlin, 1949). 
(Symmers, 1956) and secondary amyloidosis (Dahlin, 1949) from outside Africa).

The age of patients with secondary amyloid is dependent upon the time at which the underlying disease begins. In this series the range was 4 to 60 with a mean at 33 ; this is not significantly different from outside Africa (Dahlin, 1949). In the primary group the age range was 12 to 70 with a mean of 43 ; half the patients were under 50. Wright (1961) records an age range in 26 cases of primary amyloid of 14 to $65: 85 \%$ were under 40 and $50 \%$ were less than 30. Rukavina, Block, Jackson, Falls, Carey, and Curtis (1956) from America recorded one third of their cases of primary amyloid as under 50. The age of presentation of primary amyloid in Uganda is significantly earlier than that seen outside Africa.

In West Africa, Edington and Mainwaring (1964) found 11 cases of amyloidosis in a necropsy population of 3 806. In two cases no underlying cause was detected and in one of these the distribution of amyloid was that described in the classical secondary type. They found the kidney to be the organ most frequently showing heavy deposits of amyloid but commonly the adrenals and spleen were also heavily infiltrated. Other organs were rarely severely affected and in 10 cases where the thyroid was examined eight were found to have minor involvement. These findings are in general agreement with those from Uganda.

The differences in distribution suggest that some factors are operative in Ugandans which induce deposition of amyloid material in a similar fashion to that associated with chronic infectious diseases. Certainly malaria and filariasis are widespread in Uganda, many of the population contracting these diseases at an early age. The unusual levels of serum proteins in the Africans (McFarlane, Talerman, and Steinberg, 1970) are possibly a manifestation of continual bombardment by such infective agents, coupled perhaps with immunological defects as a result of malnutrition (Mugerwa, 1971). In addition, evidence seems to be accumulating that amyloidosis is often associated with deficiency of delayed hyper- $\stackrel{\stackrel{0}{*}}{\overrightarrow{0}}$ sensitivity reactions (Muckle, 1968; Cathcart, $\stackrel{-}{-}$ Mullarkey, and Cohen, 1970; Lehner, Cameron, $\overrightarrow{\vec{F}}$ and Ward, 1970).

Thus we might suggest that early and prolonged exposure to infections and infestations, possibly $\overline{\frac{0}{0}}$. complicated by defects in cellular immunity, could $\widehat{\varnothing}$ be responsible for the different distribution and $\varrho$ earlier onset of primary amyloidosis in Ugandans.

References

Abraham, S., Damodaran, V. N., and Sharma, V. N. (1967). Amyloid goitre. Indian J. Chest Dis., 9, 233-235.

Arean, V. M., and Klein, R. E. (1961). Amyloid goitre. Amer.J. clin. i Path., 36, 341-355.

Beckmann, O. (1858). Ein Fall von amyloider Degeneration. $\infty$ Virchows Arch. path. Anat., 13, 94-98.

Cathcart, E. S., Mullarkey, M., and Cohen, A. S. (1970). Amyloidosis: an expression of immunological tolerance. Lancet, 2, 639-640. 0

Dahlin, D. C. (1949). Secondary amyloidosis. Ann. intern. Med., 음 105-119.

Edington, G. M., and Mainwaring, A. R. (1964). Amyloidosis in $D$ Western Nigeria. Puth. et Microbiol. (Basel), 27, 841-847.

Hunter, W. R., McDougall, C. D. M., and Winston Evans. R. (1968). Amyloid goitre. Brit. J. Surg., 55, 885-887.

Lehner, T., Cameron, J. S., and Ward, R. G. (1970). Lymphocyte $\rightarrow$ transformation in patients with amyloidosis. Clin. exp. Immunol., 6, 439-444.

McFarlane, H., Talerman, A., and Steinberg, A. G. (1970). Immuno- N globulins in Jamaicans and Nigerians with immunogenetic typing of myeloma and lymphoma in Jamaicans. J. clin. Path., 23, 124-126.

Muckle, T. J. (1968). Impaired immunity in the aetiology of amyloidosis: a speculative review. Israel J. med. Sci., 4, 1020-1034.

Mugerwa, J. W. (1971). The lymphoreticular system in kwashiorkor. J. Path., 105, 105-109.

Rukavina, J. G., Block, W. D., Jackson, C. E., Falls, H. F., Carey, J. H., and Curtis, A. C. (1956). Primary systemic amyloid: A review and an experimental, genetic and clinical study of 29 cases with particular emphasis on the familial form. Medicine (Baltimore), 35, 239-334.

von Rokitansky, C. (1855). Lehrbuch der pathologischen Anatomie, 3rd ed., vol. 1, pp. 326-328. Braumüller, Vienna.

Shapiro, S. T., Kohut, R. I., and Potter, J. M. (1971). Amyloid goiter. Arch. Otolaryng., 93, 203-208.

Symmers, W. St. C. (1956). Primary amyloidosis: a review. J. clin. Path., 9, 187-211.

Templeton, A. C. (1970). To be published.

Walker, G. A. (1942). Amyloid goitre. Surg. Gynec. Obstet., 75, 374-378.

Wright, D. H. (1961). Primary amyloidosis and renal vein thrombosis with a review of amyloidosis in Uganda A fricans. E. Afr. med. $J ., 38,441-448$. 